\title{
THE EPIGENOME AT THE CROSSROAD BETWEEN SOCIAL FACTORS, INFLAMMATION AND OSTEOPOROSIS RISK
}

\section{José A. Riancho ${ }^{1,2}$ and Sharon L. Brennan-Olsen ${ }^{3,4}$}

1.Department of Medicine and Psychiatry, University of Cantabria, Santander, Spain.

2.Service of Internal Medicine, University Hospital M. Valdecilla, Valdecilla Reserach Institute (IDIVAL), Santander, Spain.

3. Australian Institute for Musculoskeletal Science (AIMSS), The University of Melbourne-Western Precinct, Melbourne, Australia

4. Department of Medicine, The University of Melbourne-Western Precinct, Melbourne, Australia

\author{
Correspondence: \\ José A. Riancho \\ Department of Medicine \\ University of Cantabria \\ Av Valdecilla sn \\ 39008 Santander, Spain \\ Fax +34942201695 \\ Email: rianchoj@unican.es
}




\section{ABSTRACT}

Both genetic and environmental factors are involved in the pathogenesis of osteoporosis and other skeletal disorders. Epidemiological studies have revealed an influence of a variety of social factors, including socioeconomic status (SES) on the risk of osteoporosis. The mechanisms involved are complex and still incompletely elucidated. Nevertheless, a variety of clinical risk factors known to influence skeletal homeostasis have been reported as being socially patterned, including nutrition, exercise, and other lifestyles, amongst others. These factors may impact the skeleton through a variety of mechanisms. Among them, there is increasing evidence for a role of DNA methylation and other epigenetic mechanisms. Indeed, several studies of human cohorts and experimental models showed that social deprivation is associated with changes in the methylation pattern of a number of genes, including some involved in stress and inflammatory responses. The influence of socioeconomic factors may be important not only during postnatal life, but also in utero, and may be transmitted to future generations by its direct effect on peripheral and target tissues and perhaps through epigenetic inheritance. Although the exact relevance of these pathways in humans has not been fully elucidated yet, they bring attention to the influences of social factors on the skeletal health of the individuals and their descendants. Therefore, they also bring forward our responsibility for both present and future generations.

KEYWORDS: EPIGENETICS, DNA METHYLATION, STRESS, OSTEOPOROSIS, SOCIOECONOMIC FACTORS, HEALTH STATUS DISPARITIES, INFLAMMATION 
A number of epidemiological studies suggest that social determinants influence skeletal health. Social determinants include factors such as lower income and/or educational attainment, or lower skilled occupations (highly associated with income and education), and these have been associated with an increased prevalence of osteoporosis and osteoporotic fractures (1-3). Furthermore, lifecourse analyses have reported that social disadvantage whilst in utero or at birth is associated with an increased risk of osteoporosis during later life $(4,5)$, thus suggesting that, in addition to non-modifiable genetic predisposition, the social environment influences the skeleton at all stages of life. Indeed, the Developmental Origins of Health and Disease (DOHaD) theory (6) provides much evidence for adverse environmental conditions increasing vulnerability to disease. Another social determinant that has strong associations with social disadvantage is lower health literacy (7). Health literacy is defined as one's ability and capacity to seek, access, understand and implement health-related information, and is beginning to attract much attention for its relevance in the osteoporosis field, especially with regards to preventive lifestyle behaviours (8) .

The data indicate that the relationship between socioeconomic factors and the skeleton is complex and non-linear, but in general are consistent with an increased osteoporosis risk in population groups with lower socioeconomic status (SES) (9-11). Furthermore, it is suggested that many clinical and lifestyle risk factors for osteoporosis are socially patterned, and thus individuals of lower SES are likely to have a disproportionately greater risk. However, osteoporosis risk may be exacerbated by more than direct biological insults on bone. We recently proposed a conceptual model suggesting that the biological mechanisms involved are multiple and likely result from the interaction between genetic and acquired factors and may be mediated, among others, by differences in the epigenetic marks (Figure 1).

The genome is generally constant throughout all body cells and stable from conception until death. However, changes in DNA sequence in somatic cells occasionally appear and, if they escape the control mechanisms, may lead to the development of diseases such as cancer. Sequence differences in the coding or regulatory regions of DNA have obvious consequences on gene activity. However, DNA sequence is not the only factor modulating gene transcription. In fact, epigenetic mechanisms are able to regulate gene activity in a stable manner, without implying changes in DNA sequence, and are potentially heritable through cell divisions. Among them, chromatin conformation, histone marks, noncoding RNAs and DNA methylation have received greatest attention.

The DNA double helix in chromosomes is tightly packed, bound to histone proteins, forming the nucleosomes, where DNA is wrapped around a core formed by four histones. The conformation of the chromatin contributes to modulate gene expression. When chromatin has a loose conformation, DNA is more accessible to the transcription machinery, thus allowing gene transcription. On the other hand, the condensed chromatin tends to be associated with repressed genes. Histone tails experiment a variety of post-translational modifications, such as methylation and acetylation, among others. These changes are also specifically associated with gene activity. For example, the methylation of lysines at position 9 or 27 of histone 3 bound to promoter regions is associated with gene repression, whereas the methylation of lysines at position 4 and the acetylation tend to associate with active gene transcription (12-14).

Non-coding RNAs are divided into several groups according to their length. Long noncoding RNAs (IncRNAs) are longer than 200 nucleotides and modulate gene activity at the transcriptional and post-transcriptional level (15). Among small non-coding RNAS, mature microRNAS (miRNAs) are about 20-nucleotide length molecules that bind to mRNAs bearing specific sequences. The binding of miRNAs to their target mRNAs block the translation of the mRNAs and, in some cases, induces the degradation of the mRNA. By doing so, miRNAs inhibit the synthesis of the proteins encoded by their target genes (16) .

Many cytosines in DNA are methylated, particularly those that are followed by a guanine (forming CpG dinucleotides). During cell divisions, a family of enzymes called DNA methyl-transferases are responsible for maintaining the pattern of methylation in DNA of mother cells into the DNA of daughter cells. Thus, DNA 
methylation signatures are conserved through mitosis. To some extent, methylation patterns may also be maintained through meiosis into different generation of individuals, but this is less constant.

The functions of DNA methylation have not been completely elucidated, but vary depending on the genomic regions. The methylation of intergenic regions and gene bodies likely provides stability to DNA, maintains repetitive and transposable elements silenced, and reduces the transcription of pseudogenes and transcriptional noise. However, the methylation of cytosines in gene-regulatory regions contributes, along other epigenetic mechanisms, to modulate gene expression, adapting it to the changing environmental conditions $(17,18)$. CpGs in gene bodies tend to be heavily methylated in active genes, which may help to avoid the initiation of transcription at alternative sites. Many gene promoters contain regions particularly rich in CpGs, the so-called "CpG islands". In general, the methylation of those regions is associated with gene repression, whereas when those regions remain unmethylated the genes are actively expressed $(19,20)$. However, this is by no means a universal rule. Recent studies have delineated a more complex picture. On the one hand, the inverse correlation between promoter DNA methylation and gene expression is not constant; on the other hand, the methylation of distant regulatory regions appears to have an important role in the modulation of gene expression (21). In fact, Ziller et al reported that almost $22 \%$ of $\mathrm{CpGs}$ show methylation differences across various human cell types and those differentially methylated CpGs tend to be located in enhancers and other regulatory elements (22).

Whereas the genome is constant throughout life, the epigenome, and particularly DNA methylation, changes along lifetime and across tissues. Thus, the DNA methylation pattern of a given cell depends of genetic influences (this is, DNA sequence), environmental influences, stochastic variation and some tissuespecific factors. The relative importance of these factors likely varies across genes and genomic regions, but some studies suggested that genetic factors (ie, DNA sequence variation) explain about $20 \%$ of the variation in DNA methylation, with differences across genomic regions (23)(24). Thus, epigenome-mediated interactions between genetic and environmental factors likely play a major role in the pathogenesis of common disorders, such as hypertension, obesity, diabetes, or osteoporosis. In particular, it has been hypothesized that early life experiences, determined by socioeconomic position and other factors, may induce stress reactions and other responses that modify DNA methylation patterns and consequently influence bone mass and the risk of osteoporosis in later life (10). We will provide here an overview of the evidence for this hypothesis.

\section{SOCIOECONOMIC STATUS INFLUENCES THE EPIGENOME (AND INFLAMMATION BIOMARKERS)}

SES may influence the epigenome both during early life, including pre and postnatal growth periods, as well as during middle age and older adulthood. Factors associated with SES and potentially influencing the epigenome are varied and include: nutrition, exposure to environmental toxics, smoking and other lifestyle behaviors, and stress and other psychological factors (25-27). However, measures of SES are heterogeneous, being measured, for instance, at the individual, neighborhood or wider geographic area, and by use of single parameters or aggregate indexes, in addition to other approaches, such as social stratification or life-course methodologies. Despite the high heterogeneity in this field of enquiry, SES is receiving increased attention in the field of epigenetics in recent years.

The importance of the prenatal environment on the epigenome has been highlighted by a number of cohort studies relating the environmental factors before birth with epigenetic marks later in life. For example, Tobi et al explored DNA methylation in adults who were conceived around the Dutch famine during the Second World War. Those individuals showed several differentially methylated regions, which preferentially occur at regulatory regions, and map to genes enriched for differential expression during early development and metabolism $(28,29)$. Differences in the methylation of some genes have also been reported in individuals from Bangladesh exposed to famine during gestation (30). The first 10 weeks after 
conception may represent the critical period in which mothers nutrition has a greater influence on the methylation of the offspring (31).

Studies in rats and other experimental animals have shown that the methylation patterns of genes involved in the stress response, including the glucocorticoid receptor ( $\mathrm{Nr} 3 \mathrm{c} 1$ ), Bdnf, Avp, Crh, Crhr2, and Gad1, can be modified by psychosocial factors, such as maternal care during the first week of life. These changes result into differences in the behavioral and endocrine responses to stress in adulthood (32). Indeed, evidence from a rhesus macaque model showed that dominance-rank, an indicator of social hierarchy and thus a proxy for SEP, was associated with differences in levels of chronic stress and subsequent modulation of physiological responses (33). A few human data are in line with this concept. For example, the methylation and expression of the human NR3C1 is altered in the hippocampus of victims of suicide exposed to child abuse (34). Early life experiences, such as lower socioeconomic position in childhood or parental stress during adolescence, have also been associated with specific DNA methylation profiles in adult peripheral blood or epithelial cells (reviewed in (35)).

McGuinness et al reported an association between global DNA methylation in peripheral blood cells and SES among individuals of the pSoBid cohort in Scotland. They found a lower DNA methylation in the most socio-economically deprived individuals, as well as in manual workers, in comparison with non-manual workers (36). Although the investigators did not explore the methylation of specific genes, they found an inverse correlation between global DNA methylation and the levels of the inflammatory biomarkers IL- 6 and fibrinogen. Thus, lower SES was associated with lower DNA methylation and higher levels of inflammation biomarkers. In line with this concept, Stringhini et al found that Italian subjects with low SES showed lower degrees of methylation at several inflammation-related genes, such as NFATC1, IL-1 and GPR132 (37).

Needham et al extracted nucleic acids from the monocyte fraction of the peripheral blood of large group of American individuals aged 55-94 years and explored the association of the methylation of 18 genes related to inflammation and stress responses with SES and gene expression. They found that low childhood SES was associated with DNA methylation of 4 out of 7 stress-related genes (AVP, BDNF, FKBP5, and OXTR) and 3 out of 11 inflammation-related genes (CCL1, CD1D, and F84 out of 7 stress-related genes. Similarly, methylation was associated with adult SES in 2 out of 7 stress-related genes (AVP and SLC6A4) and 5 out of 11 inflammation-related genes (CD1D, F8, KLRG1, NLRP12, and TLR3). However, in general low SES was associated with higher DNA methylation and it was inversely associated with gene expression (38). Thus, although this study supports the concept that SES influences the methylation of stress/inflammation genes, it does not support the hypothesis of higher activity of these genes in individuals of low SES.

Many studies have shown an association of psychological factors with DNA methylation patterns. For instance, Kim et al recently studied a group of men with a mean age of 73 years and found that psychological distress (measured by anxiety, depression and hostility) were associated with the methylation of several genes related to stress/inflammatory responses (ICAM-1, TLR2, iNOS, glucocorticoids receptor, $\gamma$-interferon or IL-6) (39). In line with this concept, Bam et al identified specific changes in the methylation of genes involved in immune system pathways in war veterans with posttraumatic stress disorder, a condition known to be associated with chronic low grade inflammation (40).

Nutritional habits are clearly associated with the socioeconomic position of the families and may influence the epigenome. For instance, energy balance and some vitamins may modulate the methylation of a number of genes. Thus, in obese adults, Bollati et al reported an association between dietary vitamin and fat intake with the methylation of the gene encoding the pro-inflammatory cytokine tumor necrosis factor (TNF) (41). Kok et al also showed that vitamin B12 and folic acid supplementation in older adults induced measurable changes in the methylation of some genes (42). 
These studies must be interpreted with some caution. Due to obvious feasibility reasons, they were carried out with blood, but the methylation levels in blood cells (leucocytes) may not reflect the methylation levels of other more biologically relevant tissues. Also, in several studies, authors did not consider differences in leucocyte counts as a potential confounding factor.

In general, and despite key deficiencies in this nascent field of enquiry being the heterogeneous measures of SES employed by different studies, the most extended hypothesis assumes that SES influences DNA methylation and this, in turn, influences gene expression. However, some intriguing data suggest that relationships in the opposite direction might also take place. For instance, in a study with the African cichlid fish, in which social rank dictates reproductive access, Lenkov et al showed that changes in DNA methylation induced pharmacologically were associated with ascents or descents in the social rank (43). There is no proof for a similar phenomenon of a direct role of DNA methylation in human society. However, DNA methylation has been associated with the risk of a number of disorders (including neurological and psychiatric diseases), as well as with emotional and learning abilities, which may indirectly influence social behavior and social status (44)(45)(23).

In previous paragraphs we have mentioned that changes in epigenomic marks, and specifically in DNA methylation, influence the transcription of genes involved in stress and inflammatory responses and, in consequence, modulate the intensity and duration of those responses. This has been recently illustrated by a study showing that the methylation of $58 \mathrm{CpG}$ is associated with the levels of $\mathrm{C}$-reactive protein and several cardiometabolic phenotypes (46). However, it is likely that interactions in the opposite direction also occur. Indeed, experimental and some epidemiological data suggest that cellular stress may induce changes in the epigenome (reviewed in (47)). Mitochondrial dysfunction and enhanced activation of cyclooxygenase and lipoxygenase driven by inflammation are common causes of increased oxidative stress. This has been shown to result in chromatin changes, including changes in the methylation pattern of DNA, that in turn may affect tissue function and the ability of cells to divide in an ordered manner (48).

Most studies about the influence of SES on epigenomic signatures have focused on DNA methylation. There are very few data about the potential role of social factors on other epigenetic marks, such as histone modifications or non-coding RNAs. In a small study of 28 patients with esophageal carcinoma, Stanitz et al did not found differences in miRNA expression between patients living in urban and rural areas. However, they reported that the expression of two miRNAs (miR-143 and miR-203) was reduced in the low-social group (49).

\section{EPIGENOMIC MARKS INFLUENCE BONE REMODELLING}

A proper activity of skeletal cells, and particularly osteoblasts, is critical for bone development and the accrual of bone mass during the uterine and postnatal growth periods. Likewise, an adequate balance between the bone formation activity of osteoblasts and the bone resorption activity of osteoclasts is required to maintain bone mass in adulthood. DNA methylation and other epigenetic mechanisms play a critical role in the differentiation and activity of bone cells (reviewed in (50-53)).

Some data also suggest that DNA methylation may influence bone mass and the risk of osteoporosis. Jintaridth et al reported an association between hypomethylation of Alu elements in leukocytes with postmenopausal osteoporosis (54). However, the relevance of blood cells as proxies for skeletal epigenomic studies is unclear.

An epigenome-wide study of DNA methylation in femoral bone samples showed differences in the methylation signatures of bones from patients with osteoporotic fractures and controls, particularly in some genes related to skeletal development (55). 
However, in these studies it is difficult to establish the direction of the associations and inverse causality cannot be excluded (ie, differences in methylation marks are not the cause, but the consequence of the disease). Prospective studies analyzing epigenomic marks in healthy individuals who are later followed prospectively would be ideal to work out this question. However, large, well-designed, prospective, epigenome-wide studies are not available yet. Nevertheless, some preliminary data are in favor of the influence of early-established epigenome patterns on bone mass. Nitric oxide (NO) is produced from arginine by a family of NO synthases (NOS). The muscle-relaxant and vasodilatory activity of NO are among its best-known effects. However NO has widespread effects, including bone anabolic effects, and it may contribute to transduce the influence of mechanical loads on bone cells (56)(57). Harvey et al reported that the methylation level of the endothelial-type NOS in umbilical cord obtained at birth was associated with bone mass at age of 9 years (58). This group later reported an association between methylation of the retinoid- $X$ receptor and bone mineral content in childhood (59).

Many miRNAs have been reported to participate in skeletal homeostasis, including processes such as osteoblast and osteoclast differentiation $(51,60,61)$. However, a link between bone phenotypes and SES mediated by non-coding RNAs have not been demonstrated yet.

\section{INFLAMMATION AND STRESS RESPONSES INFLUENCE BONE HOMEOSTASIS}

Stress is a physiological response that serves as a mechanism of mediation linking any given stressor to its target-organ effect. Psychosocial stressors do not directly cause a stress response; rather they need to work out through cognitive appraisal mechanisms. On the other hand, tissue lesions and other biogenic stressors elicit a stress response independently of the affective-cognitive processing (62).

The stress response is initiated by activation of limbic and cortical areas that in turn modulate hypothalamic centers and the descending autonomic pathways, including both the sympathetic and parasympathetic systems. These descending pathways modulate the activity of a variety of peripheral tissues and organs. The activation of the sympathetic system enhances the release of catecholamines by the adrenal glands, which amplifies and prolong the adrenergic response $(63,64)$.

Other endocrine changes also take part of the stress response, including increased secretion of growth hormone and $\mathrm{ADH}$, and complex changes in the metabolism of thyroid hormones. Most important, the release of CRF in the hypothalamus is enhanced; it stimulates the secretion of adrenocorticotropic hormone $(\mathrm{ACTH})$ by the pituitary, which in turn stimulates the release of glucocorticoids in the adrenal cortex.

The effects of the stress response include mobilization of energy stores and heightened vigilance. They also exert a negative feedback control that helps to finish the response when the stressor is under control. The timely activation and deactivation of stress response systems thus allow an organism to successfully manage a threat and return to normal function. An abnormal, or pathological, stress response may represent an inability to activate or deactivate the hypothalamic-pituitary-adrenal (HPA) axis, resulting in failure to manage a potentially life-threatening stressor, or such things as prolonged exposure to glucocorticoids. This in turn may have long-term consequences for behavior, memory and vulnerability to mental illness (65).

Stress response may also affect skeletal tissues. After the paper by Napal et al showing that acute stress induced a prompt inhibition of the secretion of osteocalcin by osteoblasts (66), many studies have confirmed that stress and inflammation have marked effects on skeletal homeostasis. In general, they tend to inhibit osteoblast activity and frequently enhance osteoclast-mediated resorption. Hence, a decrease in bone mass is the long-term expected consequence of persistent stress and/or inflammation (Figure 2). 
The mechanisms involved have not been completely elucidated, but they likely include physical, humoral and neural factors. Inflammatory disorders have a negative impact on body function. The activation of the HPA axis is a hallmark of the stress response. It results in increased secretion of glucocorticoid hormones. Glucocorticoids have profound effects on bone cells. High concentrations of glucocorticoids promote osteoblast and osteocyte apoptosis and consequently inhibit bone formation. They also tend to transiently increase PTH secretion and enhance osteoclast survival, thus increasing bone resorption. The effects of glucocorticoids on other tissues may also secondarily affect the skeleton. Thus, excess of glucocorticoids tend to decrease the levels of sex hormones and have a catabolic effect on muscle tissue. The resulting sarcopenia, or muscle wasting, also negatively impacts skeletal homeostasis (67).

On the other hand, several inflammatory mediators also have a negative impact on skeletal homeostasis. Thus, several pro-inflammatory cytokines, such as IL-1, IL-6 or TNF, enhance bone resorption, by direct or indirect mechanisms $(68)(69,70)$. They stimulate the release of RANKL and decrease osteoprotegerina production by several cell types present in the bone microenvironment, which, in turn, promote the differentiation of osteoclast precursors (Figure 2). At the same time, some of those cytokines tend to inhibit bone formation, acting either directly on cells of the osteoblastic lineage or increasing the production of DKK1 and other inhibitors of the bone anabolic Wnt ligands (71).

Besides the humoral-mediated effects, inflammatory diseases may result in decreased physical activity, and reduced mechanical loading of the skeleton, which has a negative impact on bone mass.

\section{PERSPECTIVES AND CONCLUSIONS}

Osteoporosis is a complex disorder resulting from the interaction of genetic and environmental factors. Despite the burgeoning evidence-base regarding the influence of SES and other social factors on the risk of osteoporosis, the mechanisms involved are likely multiple and still incompletely elucidated. Nevertheless, a variety of clinical risk factors known to influence skeletal homeostasis have been reported as being socially patterned, including nutrition, exercise and other lifestyle behaviors, and psychological factors, amongst others. These factors, in turn, may also impact the skeleton through a variety of mechanisms. Among them, there is increasing evidence for a role of DNA methylation and other epigenetic mechanisms (Figure 3 ). Indeed, several studies of human cohorts and experimental models showed that social deprivation is associated with changes in the methylation pattern of DNA in a number of genes, including some involved in stress and inflammatory responses.

Several lines of evidence suggest that adverse experiences in early life, such as those that frequently occur in population groups in the lowest socioeconomic strata (including maternal stress, anxiety and depression during pregnancy, maternal lifetime history of depression, insecure mother-child bonds and increased psychosocial risk), may permanently affect the ability of the body to mount a normal stress response, resulting in increased activation of the HPA axis after stressful situations (65). Therefore, the influence of socioeconomic factors may be important not only during early postnatal, adolescence and adult life, but also in utero and may be transmitted to future generations by its direct effect on peripheral and target tissues and perhaps through epigenetic inheritance. The extent to which methylation signatures is transmitted transgenerationally is unclear. As mentioned above, many studies suggest that in utero experiences have consequences in adulthood. There is also some evidence suggesting that those experiences may influence the phenotype of the descendants. For example, studies of the Overkalix cohort in Sweden have shown an association between the food supply of the grandmothers and the cardiovascular mortality of the grandchildren (72). However, a definitive confirmation of such transgenerational inheritance of non-imprinted genes has not been obtained in humans yet 
Although much more research is needed in this field, including the analysis of epigenomic marks in skeletal tissues, globally, already available studies represent the biological underpinning for the role of social factors in the skeletal health of present individuals and their descendants. Understanding that the epigenetic signature is influenced by a multitude of environmental factors across the lifespan is imperative to efforts aimed at reducing the burden and prevalence of osteoporosis. Furthermore, elucidation of the mechanistic crossroads between the epigenome and social determinants may support the identification of various entry points for interventions in order to reduce the social gradient of osteoporosis. Furthermore, the recognition of these epigenome-mediated sociobiological interactions bring forward our responsibility for both present and future generations.

\section{FUNDING AND CONFLICTS OF INTEREST}

JAR is funded by Instituto de Salud Carlos III (PI12/615, PI16/915, that can be co-funded by EU FEDER funds). SLB-O is funded by a National Health and Medical Research Council (NHMRC) of Australia Career Development Fellowship (1107510).

Authors declare that they do not have conflicts of interest relevant to this paper.

The article does not contain any studies with human or animal subjects performed by the any of the authors has been included in the manuscript. 


\section{ABBREVIATIONS}

ACTH: adrenocorticotropic hormone

AVP (ADH): arginine vasopressin (antidiuretic hormone)

BDNF: brain derived neurotrophic factor

$\mathrm{CRH}$ : corticotropin releasing hormone

CRHR2: corticotropin releasing hormone receptor 2

DNMT: DNA methyl-transferase

F8: coagulation factor VIII

FKBP5: FK506 binding protein 5

GAD: glutamate decarboxylase

GPR132: G protein-coupled receptor 132

ICAM-1: intercellular adhesion molecule 1

IL: interleukin

KLRG1: killer cell lectin like receptor G1

NFATC1: nuclear factor of activated T-cells 1

NLRP12: NLR family pyrin domain containing 12

NOS: nitric oxide synthase

$\mathrm{Nr} 3 \mathrm{c} 1$ : nuclear receptor subfamily 3 group $\mathrm{C}$ member 1

OXTR: oxytocin receptor

RANKL: Receptor activator of nuclear factor kappa-B ligand (TNFSF11)

SES: socio-economic status

SLC6A4: solute carrier family 6 member 4

TLR: toll like receptor

TNF: tumor necrosis factor 


\section{FIGURE LEGENDS}

Figure 1. A conceptual model of the relationship between socioeconomic factors and fracture risk. Reproduced from Bone with permission (10).

Figure 2. Influence of stress and inflammatory responses on skeletal homeostasis.

Figure 3. Multiple pathways and mechanisms involved in the interaction between social factors and the skeleton. The potential role of epigenomic mechanisms is emphasized. Dashed lines represent relations that have not been confirmed yet. Dotted red lines represent "backward" pathways by which biological factors may influence socioeconomic status. 


\section{REFERENCES}

1. Gur A, Sarac AJ, Nas K, Cevik R. The relationship between educational level and bone mineral density in postmenopausal women. BMC Fam Pract. 2004;5:18.

2. Amiri M, Nabipour I, Larijani B, Beigi S, Assadi M, Amiri Z, et al. The relationship of absolute poverty and bone mineral density in postmenopausal Iranian women. Int J Public Health. 2008; 53:290-296.

3. Crandall C, Merkin S, Seeman T, Greendale GA, Binkley N, Karlamangla AS. Socioeconomic status over the life-course and adult bone mineral density: The Midlife in the U.S. Study. Bone. 2012; 51(1):107-13.

4. Goodfellow LR, Earl S, Cooper C, Harvey NC. Maternal diet, behaviour and offspring skeletal health. Int J Environ Res Public Health. 2010;53:290-6.

5. Harvey N, Dennison E, Cooper C. Osteoporosis: a lifecourse approach. J Bone Miner Res. 2014; 29(9):1917-25.

6. $\quad$ Barker DJP. The origins of the developmental origins theory. J Intern Med. 2007;261:412-7.

7. Beauchamp A, Buchbinder R, Dodson S, Batterham RW, Elsworth GR, Mcphee C, et al. Distribution of health literacy strengths and weaknesses across socio-demographic groups: a cross-sectional survey using the Health Literacy Questionnaire (HLQ). BMC Public Health. 2015;15:678.

8. Hosking S, Buchbinder R, Pasco J, Williams L, Brennan-Olsen S. The Role of Health Literacy in the Treatment of Osteoporosis. J Bone Miner Res 2016;31:1909.

9. Vestergaard P, Rejnmark L, Mosekilde L. Socioeconomic aspects of fractures within universal public healthcare: a nationwide case-control study from Denmark. Scand J Public Health. 2006;34:371-7.

10. Brennan-Olsen SL, Page RS, Berk M, Riancho JA, Leslie WD, Wilson SG, et al. DNA methylation and the social gradient of osteoporotic fracture : A conceptual model. Bone. 2016;84:204-12.

11. Brennan SL, Holloway KL, Williams LJ, Kotowicz MA, Bucki-Smith G, Moloney DJ, et al. The social gradient of fractures at any skeletal site in men and women: data from the Geelong Osteoporosis Study Fracture Grid. Osteoporos Int 2015;26(4):1351-9.

12. Araki Y, Mimura T. The Histone Modification Code in the Pathogenesis of Autoimmune Diseases. Mediators Inflamm 2017;2017:1-12.

13. Zhang T, Cooper S, Brockdorff $N$. The interplay of histone modifications - writers that read. EMBO Rep 2015;16(11):1467-81.

14. Turinetto $\mathrm{V}$, Giachino $\mathrm{C}$. Histone variants as emerging regulators of embryonic stem cell identity. Epigenetics. 2015;10(7):563-73.

15. Schmitz SU, Grote P, Herrmann BG. Mechanisms of long noncoding RNA function in development and disease. Cell Mol Life Sci. 2016;73(13):2491-509.

16. Hassan MQ, Tye CE, Stein GS, Lian JB. Non-coding RNAs: Epigenetic regulators of bone development and homeostasis. Bone 2015;81:746-56.

17. Huh I, Zeng J, Park T, Yi S V. DNA methylation and transcriptional noise. Epigenetics Chromatin. 2013;6(1):9.

18. Calvanese V, Lara E, Kahn A, Fraga MF. The role of epigenetics in aging and age-related diseases. Ageing Res Rev. 2009;8(4):268-76.

19. Jones PA. Functions of DNA methylation: islands, start sites, gene bodies and beyond. Nat Revews Genet. 2012;13(7):484-92.

20. Deaton AM, Webb S, Kerr AR, Illingworth RS, Guy J, Andrews R, et al. Cell type-specific DNA methylation at intragenic CpG islands in the immune system. Genome Res. 2011;21(7):1074-86.

21. Reddington JP, Pennings $S$, Meehan RR. Non-canonical functions of the DNA methylome in gene regulation. Biochem J. 2013;451(1):13-23.

22. Ziller MJ, Gu H, Muller F, Donaghey J, Tsai LT, Kohlbacher O, et al. Charting a dynamic DNA methylation landscape of the human genome. Nature. 2013; 500:477-81.

23. Chiarella J, Tremblay RE, Szyf M, Provencal N, Booij L. Impact of Early Environment on Children's Mental Health: Lessons From DNA Methylation Studies With Monozygotic Twins. Twin Res Hum Genet. 2015;18(6):1-12.

24. van Dongen J, Nivard MG, Willemsen G, Hottenga J-J, Helmer Q, Dolan C V, et al. Genetic and 
environmental influences interact with age and sex in shaping the human methylome. Nat Commun 2016;7:11115.

25. Vaiserman A. Epidemiologic evidence for association between adverse environmental exposures in early life and epigenetic variation: a potential link to disease susceptibility? Clin Epigenetics 2015; $7(1): 96$.

26. Vaiserman AM. Epigenetic programming by early-life stress: Evidence from human populations. Dev Dyn. 2015;244(3):254-65.

27. Demetriou CA, van Veldhoven K, Relton C, Stringhini S, Kyriacou K, Vineis P. Biological embedding of early-life exposures and disease risk in humans: A role for DNA methylation. Eur J Clin Invest. 2015; 45(3):303-32.

28. Heijmans BT, Tobi EW, Stein AD, Putter H, Blauw GJ, Susser ES, et al. Persistent epigenetic differences associated with prenatal exposure to famine in humans. Proc Natl Acad Sci U S A. 2008; 105(44):17046-9.

29. Tobi EW, Goeman JJ, Monajemi R, Gu H, Putter H, Zhang Y, et al. DNA methylation signatures link prenatal famine exposure to growth and metabolism. Nat Commun 2014;5:5592.

30. Finer S, lqbal MS, Lowe R, Ogunkolade BW, Pervin S, Mathews C, et al. Is famine exposure during developmental life in rural Bangladesh associated with a metabolic and epigenetic signature in young adulthood? A historical cohort study. BMJ Open 2016;6(11):e011768.

31. Tobi EW, Slieker RC, Stein AD, Suchiman HED, Eline Slagboom P, Van Zwet EW, et al. Early gestation as the critical time-window for changes in the prenatal environment to affect the adult human blood methylome. Int J Epidemiol. 2015;44(4):1211-23.

32. Weaver ICG, Cervoni N, Champagne FA, D'Alessio AC, Sharma S, Seckl JR, et al. Epigenetic programming by maternal behavior. Nat Neurosci 2004;7(8):847-54.

33. Tung J, Barreiro LB, Johnson ZP, Hansen KD, Michopoulos V, Toufexis D, et al. Social environment is associated with gene regulatory variation in the rhesus macaque immune system. Proc Natl Acad Sci U S A. 2012;109(17):6490-5.

34. McGowan PO, Sasaki A, D'Alessio AC, Dymov S, Labonté B, Szyf M, et al. Epigenetic regulation of the glucocorticoid receptor in human brain associates with childhood abuse. Nat Neurosci 2009; 12(3):342-8.

35. Provencal N, Booij L, Tremblay RE. The developmental origins of chronic physical aggression: biological pathways triggered by early life adversity. J Exp Biol 2015; 218(Pt 1):123-33.

36. Mcguinness D, Mcglynn LM, Johnson PCD, Macintyre A, Batty GD, Burns H, et al. Socio-economic status is associated with epigenetic differences in the pSoBid cohort. Int J Epidemiol. 2012; 41(1):151-60.

37. Stringhini S, Polidoro S, Sacerdote C, Kelly RS, Van Veldhoven K, Agnoli C, et al. Life-course socioeconomic status and DNA methylation of genes regulating inflammation. Int J Epidemiol. 2015; 44(4):1320-30.

38. Needham BL, Smith JA, Zhao W, Wang X, Kardia SLR, Shively CA, et al. Life course socioeconomic status and DNA methylation in genes related to stress reactivity and inflammation : The multi-ethnic study of atherosclerosis. Epigenetics. 2015;10:958-69.

39. Kim D, Kubzansky LD, Baccarelli A, Sparrow D, Spiro A, Tarantini L, et al. Psychological factors and DNA methylation of genes related to immune/inflammatory system markers: the VA Normative Aging Study. BMJ Open 2016;6(1):e009790.

40. Bam M, Yang X, Zumbrun EE, Zhong $Y$, Zhou J, Ginsberg JP, et al. Dysregulated immune system networks in war veterans with PTSD is an outcome of altered miRNA expression and DNA methylation. Sci Rep 2016;6:31209.

41. Bollati V, Favero C, Albetti B, Tarantini L, Moroni A, Byun HM, et al. Nutrients intake is associated with DNA methylation of candidate inflammatory genes in a population of obese subjects. Nutrients. 2014;6(10):4625-39.

42. Kok DE, Dhonukshe-Rutten RA, Lute C, Heil SG, Uitterlinden AG, van V der, et al. The effects of longterm daily folic acid and vitamin B12 supplementation on genome-wide DNA methylation in elderly subjects. Clin Epigenetics. 2015;7:121. 
43. Lenkov K, Lee MH, Lenkov OD, Swafford A, Fernald RD. Epigenetic DNA methylation linked to social dominance. PLoS One. 2015;10(12):1-11.

44. Hoffmann A, Spengler D. DNA memories of early social life. Neuroscience 2014;264:64-75.

45. Swartz JR, Hariri AR, Williamson DE. An epigenetic mechanism links socioeconomic status to changes in depression-related brain function in high-risk adolescents. Mol Psychiatry. 2017; 22:209-214.

46. Ligthart S, Marzi C, Aslibekyan S, Mendelson MM, Conneely KN, Tanaka T, et al. DNA methylation signatures of chronic low-grade inflammation are associated with complex diseases. Genome Biol 2016; 17(1):255.

47. Kreuz S, Fischle W. Oxidative stress signaling to chromatin in health and disease. Epigenomics 2016; 8(6):843-62.

48. Planello AC, Singhania R, Kron KJ, Bailey SD, Roulois D, Lupien M, et al. Pre-neoplastic epigenetic disruption of transcriptional enhancers in chronic inflammation. Oncotarget 2015;7(13):1-15.

49. Stánitz É, Juhász K, Gombos K, Gőcze K, Tóth C, Kiss I. Alteration of miRNA Expression Correlates with Lifestyle, Social and Environmental Determinants in Esophageal Carcinoma. Anticancer Res. 2015;35:1091-7.

50. Delgado-Calle J, Riancho JA. The Role of DNA Methylation in Common Skeletal Disorders. Biology (Basel) [Internet]. 2012;1:698-713.

51. Delgado-Calle J, Garmilla P, Riancho JA. Do epigenetic marks govern bone mass and homeostasis? Curr Genomics. 2012;13(3):252-63.

52. Delgado-Calle J, Sanudo C, Bolado A, Fernandez AF, Arozamena J, Pascual-Carra MA, et al. DNA methylation contributes to the regulation of sclerostin expression in human osteocytes. J Bone Miner Res. 2012;27:926-37.

53. Lian JB, Stein GS, van Wijnen AJ, Stein JL, Hassan MQ, Gaur T, et al. MicroRNA control of bone formation and homeostasis. Nat Rev Endocrinol. 2012;8(4):212-27.

54. Jintaridth $P$, Tungtrongchitr R, Preutthipan S, Mutirangura A. Hypomethylation of Alu elements in post-menopausal women with osteoporosis. PLoS One 2013;8(8):e70386.

55. Delgado-Calle J, Fernandez AF, Sainz J, Zarrabeitia MT, Sanudo C, Garcia-Renedo R, et al. Genomewide profiling of bone reveals differentially methylated regions in osteoporosis and osteoarthritis. Arthritis Rheum. 2013;65:197-205.

56. Delgado-Calle J, Riancho JA, Klein-Nulend J. Nitric oxide is involved in the down-regulation of SOST expression induced by mechanical loading. Calcif Tissue Int. 2014;94:414-22.

57. Riancho JA, Salas E, Zarrabeitia MT, Olmos JM, Amado JA, Fernandez-Luna JL, et al. Expression and functional role of nitric oxide synthase inhibitors in osteoblast-like cells. J Bone Miner Res. 1995; 10:439-46.

58. Harvey NC, Lillycrop KA, Garratt E, Sheppard A, McLean C, Burdge G, et al. Evaluation of methylation status of the eNOS promoter at birth in relation to childhood bone mineral content. Calcif Tissue Int. 2012;90:120-7.

59. Harvey NC, Sheppard A, Godfrey KM, McLean C, Garratt E, Ntani G, et al. Childhood bone mineral content is associated with methylation status of the RXRA promoter at birth. J Bone Miner Res. 2014; 29(3):600-7.

60. Papaioannou G. MiRNAs in bone development. Curr Genomics. 2015;16(6):427-34.

61. Seeliger C, Er B, van Griensven M. miRNAs Related to Skeletal Diseases. Stem Cells Dev. 2016;25:1261-8.

62. Herman JP, Mcklveen JM, Ghosal S, Kopp B, Wulsin A, Makinson R, et al. Regulation of the hypothalamic-pituitary-adrenocortical stress response. Compr Physiol. 2016;6(2):603-21

63. Gold PW. The organization of the stress system and its dysregulation in depressive illness. Mol Psychiatry 2015;20(1):32-47.

64. Waltes $R$, Chiocchetti AG, Freitag $C M$. The neurobiological basis of human aggression: A review on genetic and epigenetic mechanisms. Am J Med Genet Part B Neuropsychiatr Genet. 2016; 171(5):650-75.

65. Hunter AL, Minnis $\mathrm{H}$, Wilson P. Altered stress responses in children exposed to early adversity: a systematic review of salivary cortisol studies. Stress 2011;14(6):614-26. 
66. Napal J, Amado JA, Riancho JA, Olmos JA, Gonzalez-Macias J. Stress decreases the serum level of osteocalcin. Bone Miner. 1993;21:113-8.

67. Hartmann K, Koenen M, Schauer S, Wittig-Blaich S, Ahmad M, Baschant U, et al. Molecular Actions of Glucocorticoids in Cartilage and Bone During Health, Disease, and Steroid Therapy. Physiol Rev 2016;96(2):409-47.

68. Lorenzo J, Horowitz M, Choi Y. Osteoimmunology: Interactions of the bone and immune system. Endocr Rev. 2008;29(4):403-40.

69. Schett G, Dayer J-M, Manger B. Interleukin-1 function and role in rheumatic disease. Nat Rev Rheumatol 2015;12(1):14-24.

70. Zupan J, Jeras M, Marc J. Osteoimmunology and the influence of pro-inflammatory cytokines on osteoclasts. Biochem Medica. 2013;23(1):43-63.

71. Pietschmann P, Mechtcheriakova D, Meshcheryakova A, Föger-Samwald U, Ellinger I. Immunology of Osteoporosis: A Mini-Review. Gerontology. 2016;62(2):128-37.

72. Bygren LO, Tinghög P, Carstensen J, Edvinsson S, Kaati G, Pembrey ME, et al. Change in paternal grandmothers' early food supply influenced cardiovascular mortality of the female grandchildren. BMC Genet 2014;15(1):12. 


\section{Figure 1}

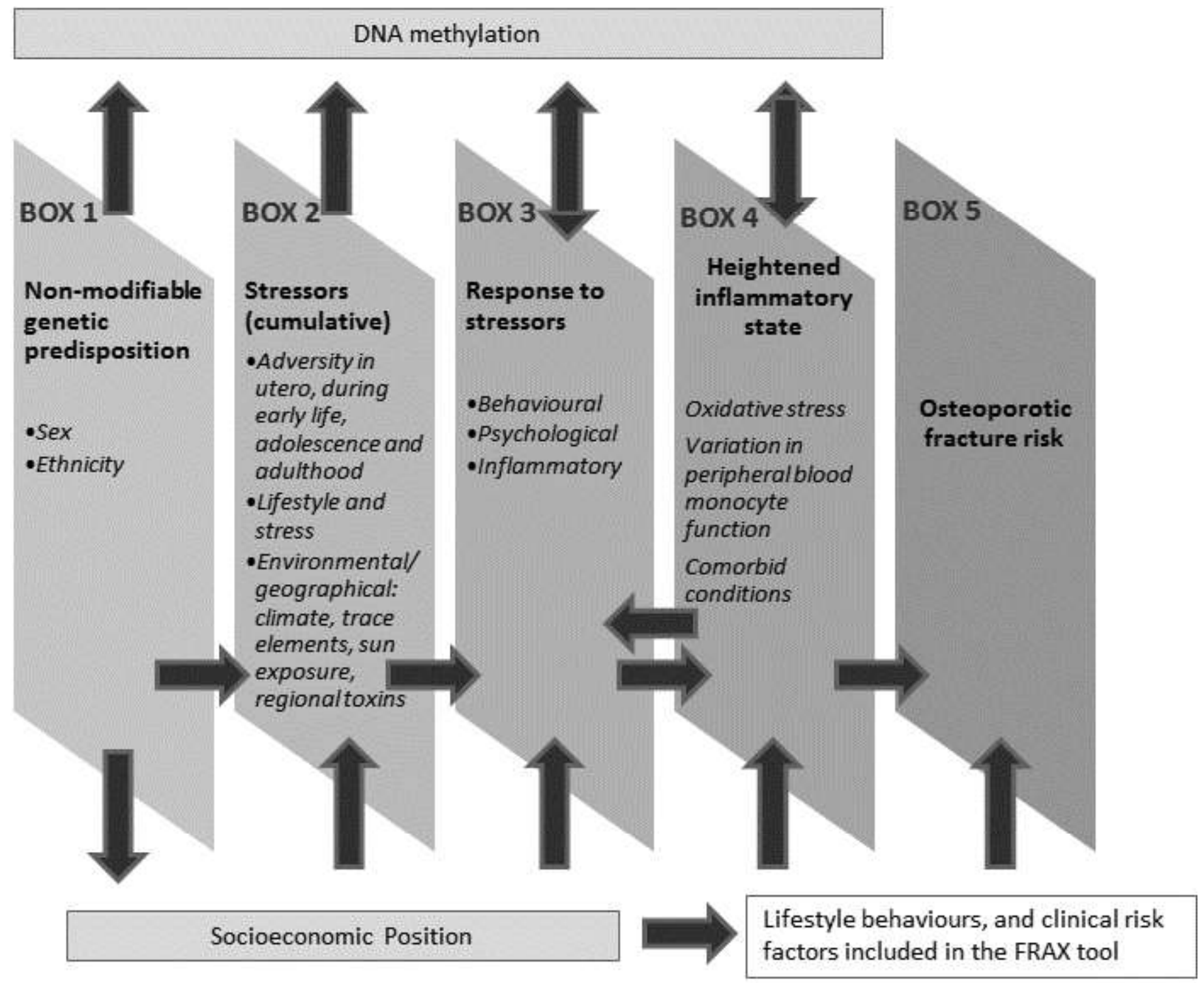




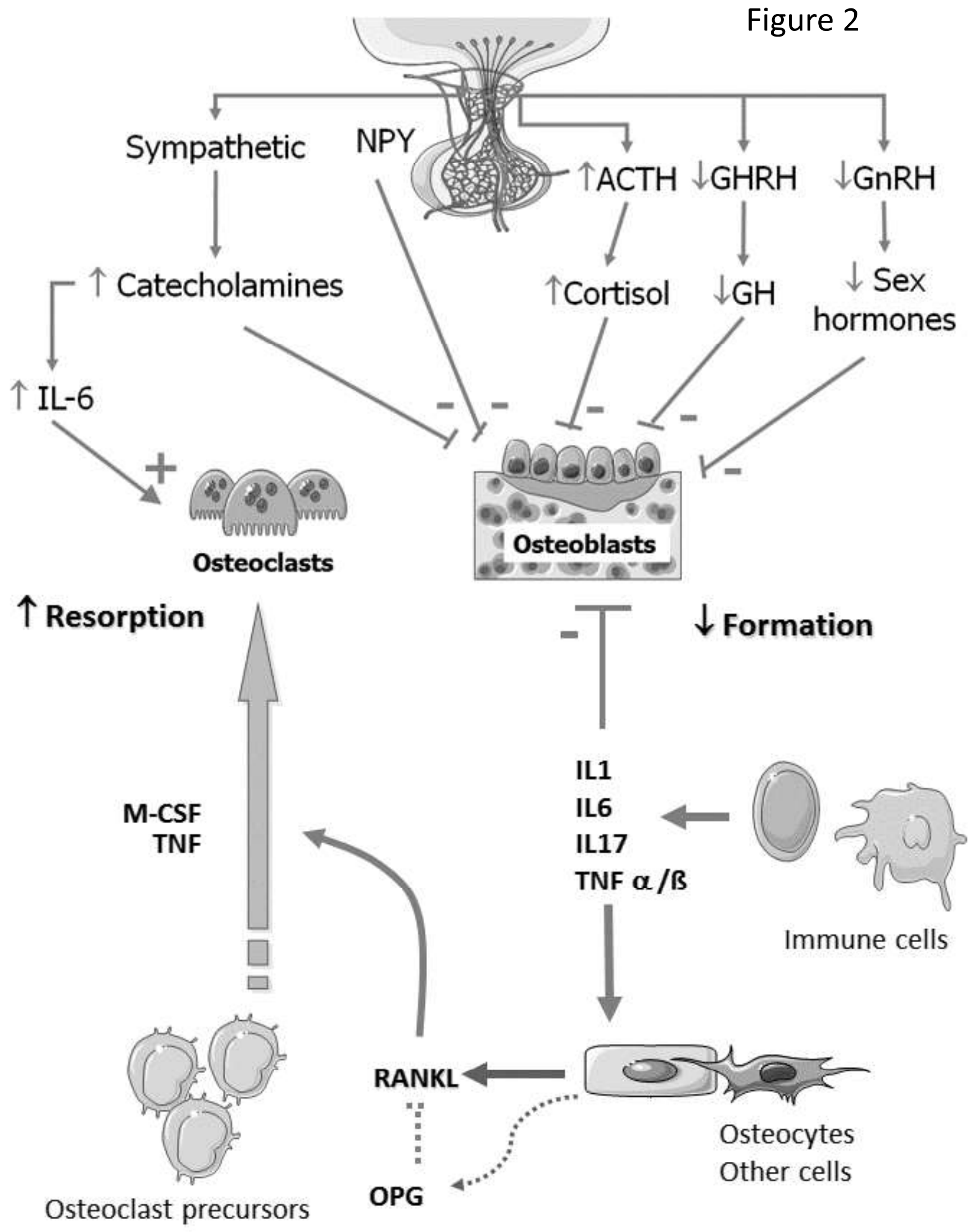


Figure 3

\section{Socioeconomic status}

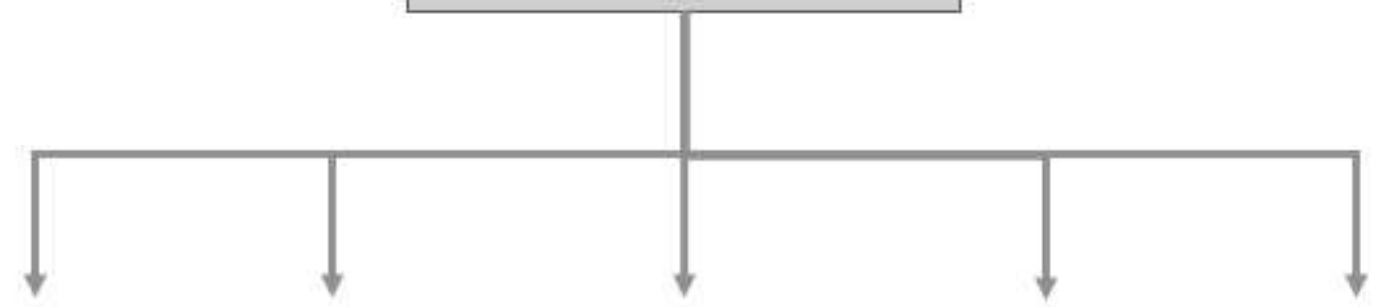

Nutrition

Diseases

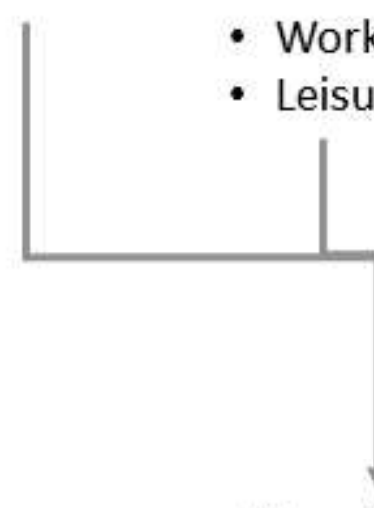

Non-skeletal tissues

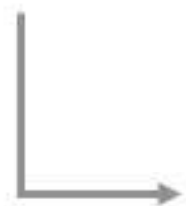

Other lifestyles

Environmental Psychological

\section{e}
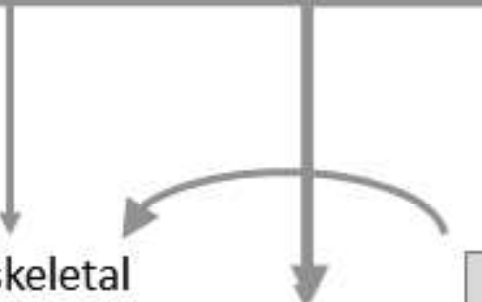

exposures factors

Genome

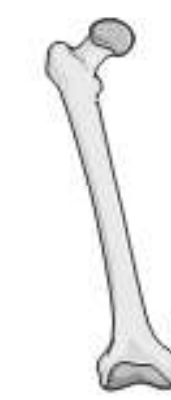

\section{Epigenome}

marks

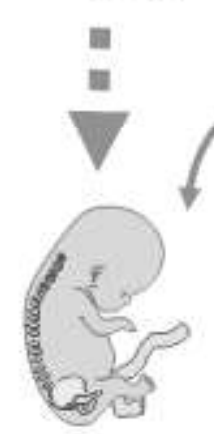

Next generations

(children, grandchildren)

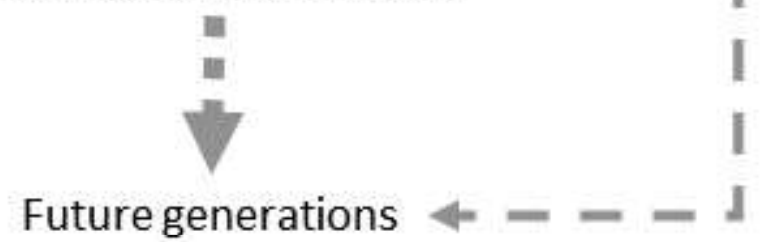

Future generations

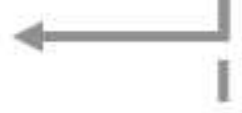

In utero 